\title{
Digital Skills Levels in 8 EU Ex-Communist Countries
}

\author{
Florina Bran ${ }^{1}$, Victor Marian Dumitrache ${ }^{2}$, Amelia Diaconu ${ }^{3}$ and Victor Adrian \\ Troacă $^{4}$ \\ ${ }^{122) 344)}$ The Bucharest University of Economic Studies, Bucharest, Romania. \\ E-mail: florinabran@yahoo.com; E-mail: victor.dumitrache@gmail.com \\ E-mail: diaconu.amelia@gmail.com; E-mail: adrian.troaca@gmail.com
}

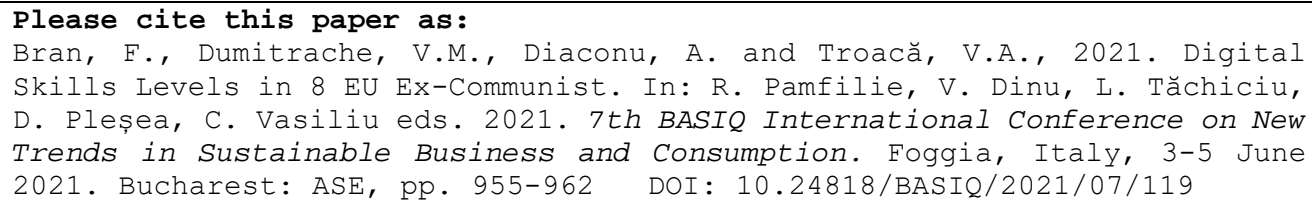

\begin{abstract}
Even if they had a similar characteristic before 1990, the countries from the communist bloc from Central and Eastern Europe have begun to differentiate one from another in terms of development after the fall of communism. Today there are many differences among them regarding their economic competitiveness. Measurements done by the European Commission through the Digital Economy and Society Index give us the chance to compare the progress registered by ex-communist countries in the last 30 years and their capacity and readiness to be competitive in the near future considering the changed brought by the rapid changes in technology and business models - the digital economy.

The purpose of this paper is to point out the major differences between $8 \mathrm{EU}$ ex-communist countries in terms of digital skills.

We will perform a comparative analysis of the indicators aggregated under Human capital (digital skills) dimension of the Digital Economy and Society Index, among $8 \mathrm{EU}$ ex-communist countries: Czech Republic, Slovenia, Slovakia, Poland, Hungary, Romania, Croatia, Bulgaria.

This article may add value by increasing the awareness regarding the importance of digital skills, especially in the context of COVID-19 crisis that made many sectors partially or totally dependent on technology, where both staff of the private and public organizations and the citizens and consumers need digital skills to provide or to consume goods and services.
\end{abstract}

Keywords: digital skills, digital economy, ex-communist countries in Europe, DESI Index. DOI: $10.24818 / B A S I Q / 2021 / 07 / 119$

\section{Introduction}

The dynamic of the economic growth has changed in the last two decades and economic theories crystalized in the $20^{\text {th }}$ century fail to come up with complete explanations (van Ark, 2016). The reason is that the new, digital economy, is totally different from the traditional economy. It is oligopolistic, global, amorphous, knowledge-driven, intangible, and very dynamic (Chohan, 2020).

The concept of Digital Economy consists of 3 main components, identified by Mesenbourg (2001):

- E-business infrastructure (software, hardware, human capital, networks, telecom, etc.).

- E-business (the way businesses are conducted, any process that is mediated by a computer and/or a network in an organization).

- E-commerce (online sales). 
The digital economy has several key features that makes it different from the traditional economy of the 20th century: mobility of intangibles, mobility of business functions (remote work, remote access to markets, remote coordination of operations) (OECD, 2014), reliance on data, network effect, multiside market, tendency to oligopoly and monopoly formation (Ciriani, 2017).

While in the academic world there are significant efforts to develop new economic theories and models to explain and predict the digital economy, governments and international organizations are focused on how to measure the performance of the digital economy and how to stimulate it.

Since 2015, the European Commission has measured the digital economy through Digital Economy and Society Index (DESI). The most recent report was published in 2020 and it is based on 2019 data that assess the status of the EU digital economy and society prior to COVID-19.

DESI aims to monitor Europe's overall digital performance and tracks the progress of EU countries regarding their digital competitiveness (EC, 2020). Measuring and tracking progress is crucial since the Commission wants a European Society powered by digital solutions that work for people and respect the EU core values, as stated in the Shaping Europe's digital future communication. (EC, 2020).

DESI is an aggregated indicator having 5 dimensions:

- Connectivity referring to: fixed broadband coverage, fixed broadband take-up, mobile broadband and broadband prices

- Human capital (digital skills) referring to: internet user skills and advanced skills

- Use of internet referring to: Citizens' use of internet services and online transactions

- Integration of digital technology referring to: Business digitisation and e-commerce

- Digital public services: e-Government

In the ranking presented in Figure no. 1 we can see that Finland, Sweden and Denmark are the most advanced digital economies in the EU while Romania, Greece and Bulgaria are the least developed. Also, all the 8 ex-communist countries included on our analysis in this paper, are below the EU average: Slovenia having the highest score among the 8, followed by Czech Republic, Croatia, Hungary, Slovakia, Poland, Romania, and Bulgaria.

Digital skills are considered the backbone of the digital economy and society. They give people the capacity to engage in basic online activities and to use digital services. The need for digital skills was strongly emphasized by the COVID-19 crisis. To various degrees, many sectors became dependent on technology. Commerce, education, healthcare, public services, and others could not be possible without technology being used by both providers and consumers. Basic and advanced digital skills need to be strengthened in the school curricula and academic offers in EU countries. As DESI 2020 report (EC, 2020) states, schools' curricula and academic offers need to give more importance to basic and advanced digital skills.

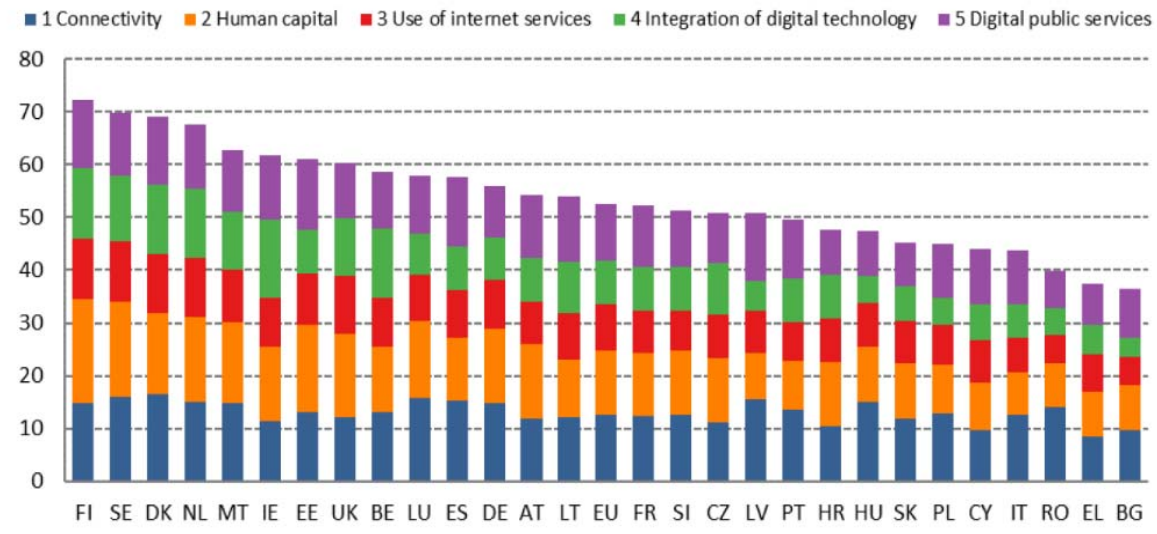

Figure no. 1. Digital Economy and Society Index, 2020

Source: DESI 2020, European Commission, p. 14 
Considering these aspects, our analysis is focused on the human capital (digital skills) dimension based on DESI 2020 data. As following, the next section of the article gives as an in depth understanding of the digital skills concept.

\section{Review of the scientific literature}

Having digital products and services developed by technology companies is not enough to develop the EU digital economy. Having skilled digital consumers is equally important for the digital economy development as innovation and technology. A digital consumer can be defined as somebody searching for and buying products and services on the Internet, consuming online content, willing to simplify the decisions they have to make and, generally, being aware of their needs (Tkaczyk, et al., 2016). The contemporary society is not characterized only by technological advancements, but also by globalization and accelerated accumulation of knowledge (van de Oudeweetering, et al., 2018).

In the work context, nonroutine, remote and interactive tasks have become more important than the manual, repetitive tasks which are being replaced through automation. (Neubert, et al., 2015).

In the digital economy, according to van Laar (et al., 2019) people (either in a domestic or work environment) use information communication technologies to access and spread information, to interact and exchange experiences with experts in learning communities, and to generate and refine their ideas. van Laar (et al., 2017) identified six generic digital skills for work setting, that are equally important for the digital consumers nowadays in the context of COVID-19 crisis. The skills are information, communication, collaboration, critical-thinking, creativity, and problem-solving skills. In the scientific literature, these generic skills have been defined as following:

- Information digital skills: skills to manage digital information, to search and to evaluate it: 1) Information searching skills: the use of search engines effectively and efficiently essential (Ananiadou, et al., 2008); 2) Information evaluation skills: the ability to sort and analyse information by criteria of relevance, reliability, and usefulness, defined as information evaluation (Hatlevik, et al., 2018); 3) Information management skills: the persons capacity to manage their email, files, documents, and other forms of digital information (Hwang et al, 2017), not only in a work setting, but also as a consumer especially since the beginning of COVID-19 outbreak.

- Communication digital skills: the ability to transmit information online and to use the best digital approach to present information to a particular audience (Ananiadou, et al., 2008). It consists of: 1) Communication expressiveness skills: the ability to create a specific impression through a digital interaction, that generates predictable outcomes (Mishra, et al., 2011); 2) Communication contact building skills: getting in contact with new people by using online channels (van Deursen, et al., 2014); 3) Communication networking skills: the ability to achieve a specific goal (such as selling products or brand awareness) by mobilizing online contacts (Wolff, et al., 2010); 4) Communication contentsharing skills: the ability to share content in the online environment, from media content to status updates, comments, blogging and vlogging. (Lee, et al., 2015)

- Critical-thinking digital skills refers to the use of evidence and reflection to make judgements about communication and information (Petrucco, et al., 2017).

- Creative digital skills: the ability to create online content by appropriately using online tools and software.

- Problem-solving digital skills: the ability to use ICTs to investigate a problem and apply knowledge in solving the problem. (Greiff, et al., 2017)

\section{Research methodology}

The current analysis that compares the $8 \mathrm{EU}$ ex-communist countries is based on Digital Economy and Society Index 2020 (DESI, 2020) raw data that can be found on https://digital-agendadata.eu/datasets/desi/visualizations. The charts are generated using the advanced data visualization tool on the platform. 
Digital skills range from basic usage skills that allow individuals to actively participate in the digital society and consume digital goods and services, up to advanced skills that qualifies the workforce to develop new digital goods and services (EU, 2020) or to deliver online/digital services. This is the reason why each indicator that builds the human capital (digital skills) dimension of DESI has two dimensions: internet user skills and advances skills and development. The indicators aggregated in the human capital dimension of DESI are: 1) Individuals with above basic level of digital skills in Information domain, 2) Individuals with at least basic digital skills in Information domain, 3) Individuals with above basic level of digital skills in Communication domain, 4) Individuals with at least basic digital skills in Communication domain, 5) Individuals with above basic level of digital skills in Problem solving domain, 6) Individuals with at least basic digital skills in Problem solving domain, 7) Individuals with above basic level of digital skills in Software domain, 8) Individuals with at least basic digital skills in Software domain, 9) Science and technology graduates. We made a comparative analysis among the $8 \mathrm{EU}$ ex-communist countries, based on 5 of these indicators, at least one from each domain.

The first 8 domain-based indicators further aggregated in 3 indicators: a) Individuals with above basic level of digital skills, b) Individuals with at least basic digital skills and c) Individuals with low level of digital skills (missing some type of basic skills). These 3 together with indicator no. 9 create the human capital aggregated indicator of DESI.

\section{Results and discussion}

Figure no. 2 presents the percentage of individuals (age 16-74) with above basic level of digital skills. They reach above basic skills level in all the four digital skills domains: information, communication, content-creation and problem-solving. Croatia (35.3\%) is the only EU ex-communist country among the 8 that is above the EU average (33.3\%). Romania (10.3\%) and Bulgaria (11.3\%) are the countries with the lowest percentage of individuals with above basic level of digital skills.

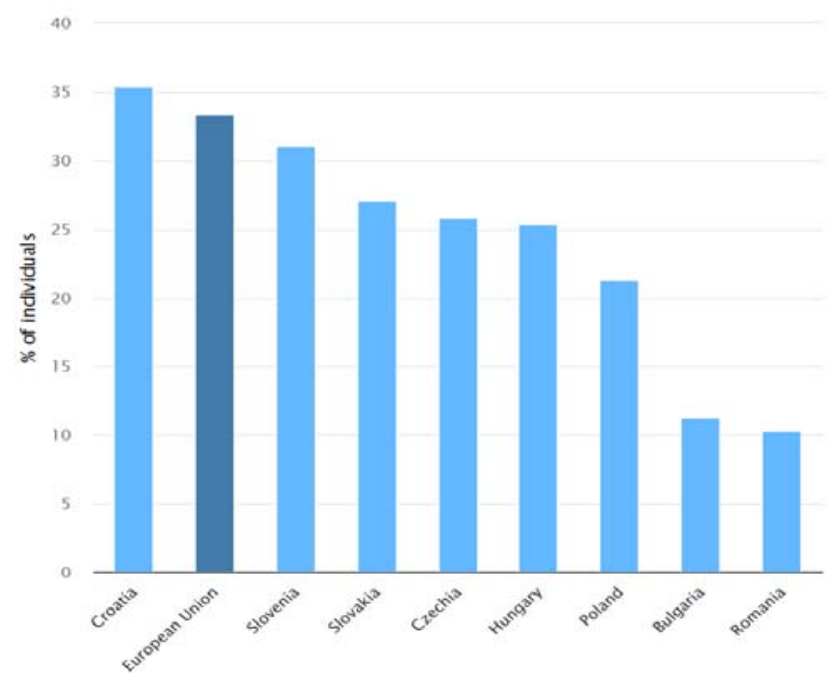

Figure no. 2. Individuals with above basic level of digital skills in 2019 Source: data visualization tool on www.digital-agenda-data.eu

In Figure no. 3 we can see that Czech Republic (75.2\%) has the highest percentage of Individuals with above basic level of digital skills in Information domain in 2019, followed by Croatia (72.1\%). The countries with the lowest scores are Romania (49.1\%) and Bulgaria (44.9\%). In the case of Romania, it means that only half of the population (age 16-74) has performed at least two of the following tasks in the last 3 months: 1) Copied or moved files or folders, 2) Saved files on Internet storage space, 3) 
Obtained information from public authorities/services' websites, 4) Finding information about goods or service, 5) Seeking health-related information.

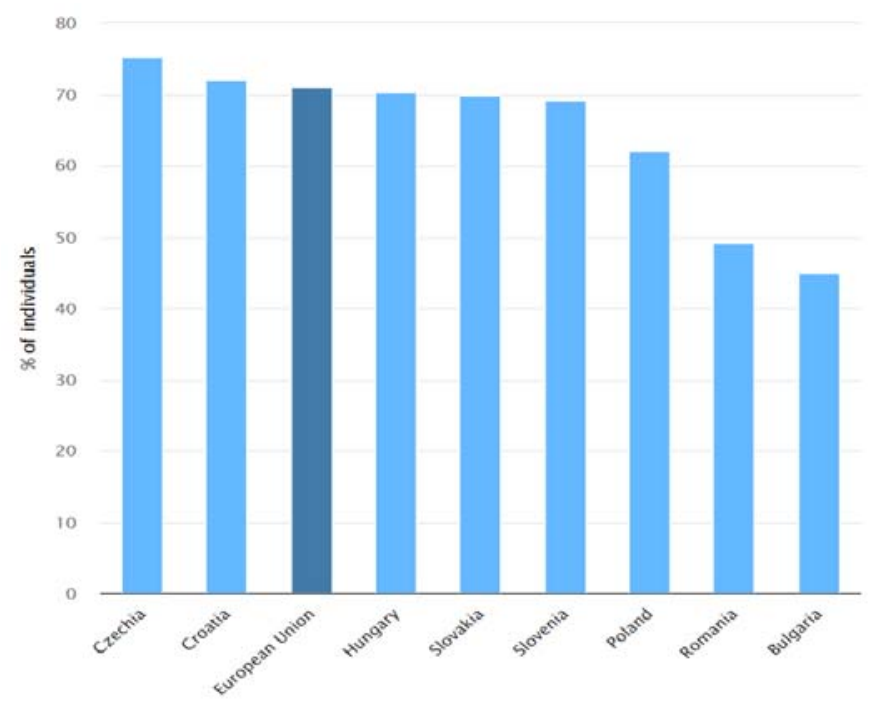

Figure no. 3. Individuals with above basic level of digital skills in Information domain Source: data visualization tool on www.digital-agenda-data.eu

In Figure no. 4 we can see that Hungary (71.1\%) has the highest percentage of individuals with above basic level of digital skills in Communication domain in 2019. The countries with the lowest scores are Romania (55.1\%) and Bulgaria (54.2\%). In the case of Bulgaria, it means that slightly more than half of the individuals aged 16 to 74 has performed at least two of the following tasks in the last 3 months: 1) Sending/receiving emails, 2) Participating in social networks, 3) Telephoning/video calls over the internet, 4) Uploading self-created content to any website to be shared.

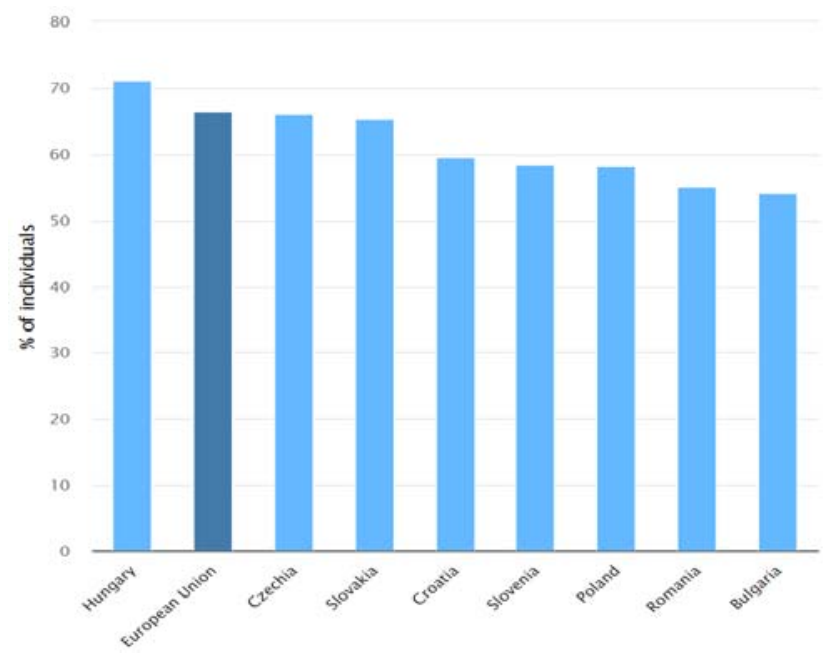

Figure no. 4. Individuals with above basic level of digital skills in Communication domain Source: data visualization tool on www.digital-agenda-data.eu

In Figure no. 5 we can see that Czech Republic (63.4\%) has the highest percentage of individuals with above basic level of digital skills in Problem solving domain in 2019. 


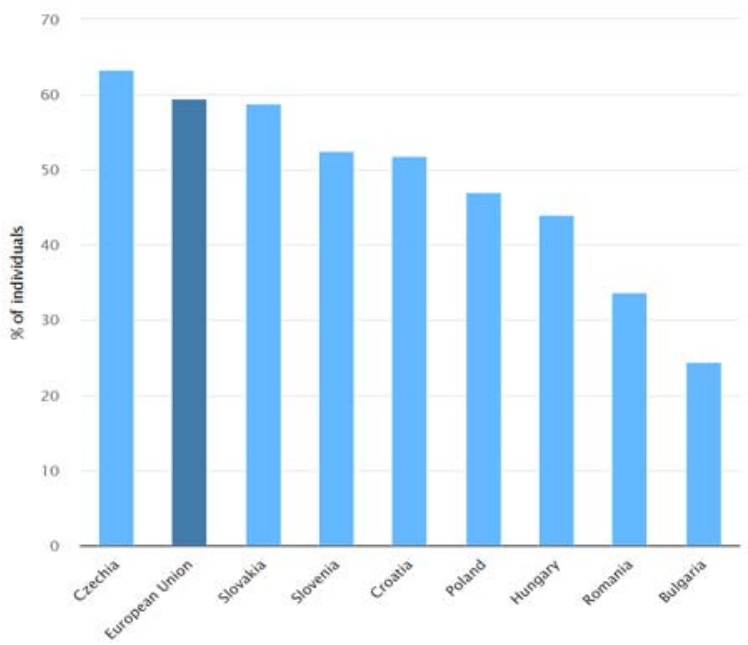

Figure no. 5. Individuals with above basic level of digital skills in Problem solving domain Source: data visualization tool on www.digital-agenda-data.eu

The countries with the lowest scores are Romania (33.6\%) and Bulgaria (24.6\%). In the case of Bulgaria, it means that only a quarter of the individuals aged 16 to 74 has performed at least one task from category a) and one from category b) in the last 3 months: a) Transferring files between computers or other devices; Installing software and applications (apps); Changing settings of any software and b) Online purchases (in the last 12 months); Selling online; Used online learning resources; Internet banking.

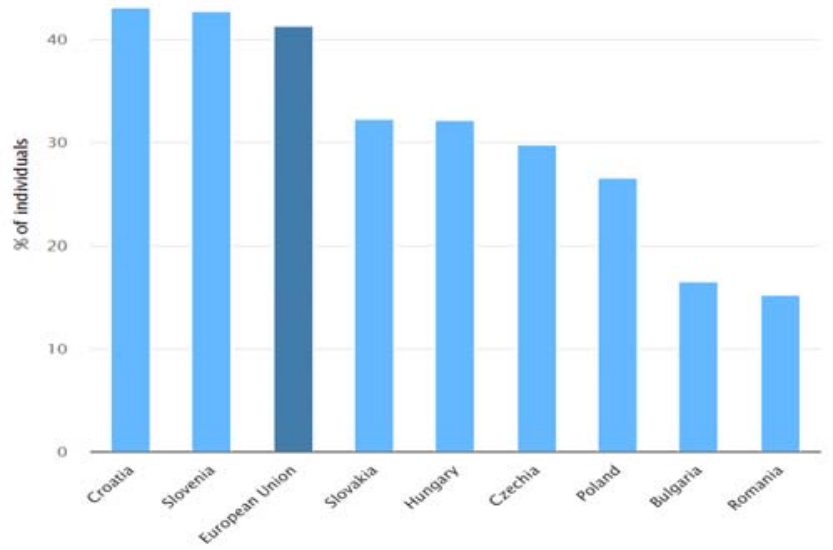

Figure no. 6. Individuals with above basic level of digital skills in Software domain Source: data visualization tool on www.digital-agenda-data.eu

In Figure no. 6 we can see that Croatia (43.1\%) has the highest percentage of individuals with above basic level of digital skills in Software domain in 2019. The countries with the lowest scores are Bulgaria (16.5\%) and Romania (15.2\%). In the case of Romania, only 1 in 15 individuals aged 16 to 74 has performed in the last 3 months at least two of the following tasks: 1) Created presentation or document integrating text, pictures, tables or charts, 2) Used advanced functions of spreadsheet to organise and analyse data (sorting, filtering, using formulas, creating charts), 3) Have written a code in a programming language. 
These 5 indicators can give us a clue about the capacity and readiness of these 8 countries to be competitive in the near future. More in-depth analysis is needed.

\section{Conclusions}

In the context of digital global economy, the digital skills of the consumers are as important as innovation and the use of technology in industry and services. All the digital goods and services require digital skills to be consumed.

As the human capital (digital skills) dimension of DESI shows us, with some exceptions, all of the 8 EU ex-communist countries are below the EU average in all of the four domains of the digital skills: information, communication, problem solving and software. Aggregating all the four domains, only Croatia, with $35.3 \%$ of the individuals aged 16 to 74 having above average digital skills, is above the EU average (33.3\%).

Among all, Romania and Bulgaria have the lowest scores in all the 4 domains, indicating that their economic competitiveness is in danger not only because the lack of digital skills triggers the lack of technology use in industry and the lack of innovation, but also because the population cannot take advantage of technology as consumers of education, healthcare, public services, commerce, and others that depend on digital solution in the context of COVID-19 outbreak.

The main limitation of this paper stays in its level of generalization. The data refer to individuals aged 16 to 74 . Further research may generate more detailed interpretations and predictions by analysing data breakdowns based on age groups, education level, employment status.

\section{References}

Ananiadou, K. and Claro, M., 2009. 21st Century Skills and Competences for New Millennium Learners in OECD Countries. [OECD Education Working Papers] https://doi.org/10.1787/218525261154.

Chohan, U.W., 2020. Some Precepts of the Digital Economy. [SSRN Scholarly Paper] Rochester, NY: Social Science Research Network. Available at: <https://papers.ssrn.com/abstract=3512353> [Accessed 18 February 2021].

Ciriani, S. and Lebourges, M., 2018. The Market Dominance of US Digital Platforms: Antitrust Implications for the European Union. [SSRN Scholarly Paper] Rochester, NY: Social Science Research Network. Available at: <https://papers.ssrn.com/abstract=2977933> [Accessed 18 February 2021].

European Commission, 2020. Digital Economy and Society Index (DESI) 2020 Thematic chapters, [online] Available at: <https://ec.europa.eu/digital-single-market/en/digital-economy-and-societyindex-desi> [Accessed 18 February 2021].

European Commission, 2020. Shaping Europe's digital future, Communication from the Commission to the European Parliament, the Council, the European Economic and Social Committee and the Committee of the Regions. Apdf] Available at: $<$ https://ec.europa.eu/info/sites/info/files/communication-shaping-europes-digital-futurefeb2020_en_3.pdf $>$ [Accessed 18 February 2021].

Greiff, S. and Funke, J., 2017. Interactive problem solving: Exploring the potential of minimal complex systems. The nature of problem solving: Using research to inspire 21st century learning. Paris: OECD Publishing.

Hatlevik, I.K. and Hatlevik, O.E., 2018. Students' evaluation of digital information: The role teachers play and factors that influence variability in teacher behaviour. Computers in Human Behavior, 83, pp.56-63.

Hwang, Y., Kettinger, W.J. and Mun, Y.Y., 2017. Personal information management effectiveness of knowledge workers: conceptual development and empirical validation. European Journal of Information Systems, 24(6), pp.588-606. 
Lee, H., Park, N. and Hwang, Y., 2015. A new dimension of the digital divide: Exploring the relationship between broadband connection, smartphone use and communication competence. Telematics and Informatics, 32(1), pp.45-56.

Messenbourg, T., 2001. Measuring the Digital Economy, Census Bureau. [pdf] Available at: $<$ https:/www.census.gov/content/dam/Census/library/working-papers/2001/econ/umdigital.pdf> [Accessed 14 March 2021].

Mishra, P. and Kereluik, K., 2011. What 21st century learning? A review and a synthesis. In Proceedings of society for information technology \& teacher education international conference 2011, AACE International, Chesapeake, pp.3301-3312.

Neubert, J., Mainert, J., Kretzschmar, A. and Greiff, S., 2015. The Assessment of 21st Century Skills in Industrial and Organizational Psychology: Complex and Collaborative Problem Solving. Industrial and Organizational Psychology, 8(2), pp.238-268.

OECD, 2014. "The digital economy, new business models and key features". Addressing the Tax Challenges of the Digital Economy. OECD/G20 Base Erosion and Profit Shifting Project. Paris: OECD Publishing. pp.69-97.

Petrucco, C. and Ferranti, C., 2017. Developing critical thinking in online search. Journal of e-Learning and Knowledge Society, 13(3), pp.35-45.

Tkaczyk, J., 2016. Digital Consumer: Trends and Challenges. In The Impact of the Digital World on Management and Marketing, p. 353.

van Ark, B., 2016. The Productivity Paradox of the New Digital Economy. International Productivity Monitor, 31, pp.3-18.

van Deursen, A.J.A.M., Courtois, C. and van Dijk, J.A.G.M., 2014, Internet skills, support sources and beneficial Internet use. International Journal of Human-Computer Interaction, 30(4), pp.278-290.

Oudeweetering, K. and Voogt, J., 2018. Teachers' conceptualization and enactment of twenty-first century competences: exploring dimensions for new curricula. The Curriculum Journal, 29(1), pp.116-133.

van Laar, E., van Deursen, A.J.A.M., van Dijk, J.A.G.M. and de Haan, J., 2019. Determinants of 21 stcentury digital skills: A large-scale survey among working professionals. Computers in Human Behavior, 100, pp.93-104.

Wolff, H.-G. and Moser, K., 2010. Do specific types of networking predict specific mobility outcomes? A two-year prospective study. Journal of Vocational Behavior, 77(2), pp.238-245. 